\title{
Review of rainfall frequency estimation methods
}

\author{
Cecilia Svensson and David A. Jones \\ Centre for Ecology and Hydrology, Wallingford, OX10 8BB, UK
}

19 October 2010

\begin{abstract}
This review outlines nationwide methods for point rainfall frequency estimation currently in use in nine different countries: Canada, Sweden, France, Germany, the United States, South Africa, New Zealand, Australia and the United Kingdom. For the United Kingdom, the Flood Studies Report method from 1975 is described as well as the current Flood Estimation Handbook method. The focus is on return periods relevant to reservoir design, in the region of 100 to 10,000 years. There is considerable difficulty in estimating long return period rainfalls from short data records and there is no obviously "best" way of doing it. Each country's method is different, but most use some form of regionalisation to transfer information from surrounding sites to the target point. Several of the methods are variations of a regionalisation method that combines a local estimate of an index variable (typically the mean or median annual maximum rainfall) with a regionally-derived growth curve to obtain a design rainfall estimate. Three of the methods use regions centred on the site of interest, rather than fixed-boundary regions. Different statistical distributions and fitting methods are used, with the Generalised Extreme Value distribution being the most common.
\end{abstract}

Keywords: extreme, frequency estimation, methodology, rainfall

Corresponding author: Cecilia Svensson, csve@ceh.ac.uk

Accepted for publication in Journal of Flood Risk Management (Chartered
Institution of Water and Environmental Management, Blackwell Publishing)

The definitive version is available at www.blackwell-synergy.com

http://onlinelibrary.wiley.com/doi/10.1111/j.1753-318X.2010.01079.x/abstract 


\section{Introduction}

This review was carried out as part of a project on reservoir safety in the United Kingdom (UK) and is concerned with methods for the estimation of point rainfalls. The establishment of the Flood Studies Report (FSR) (NERC 1975) as an industry standard, followed by its various upgrades and modifications, and later the Flood Estimation Handbook (FEH) (Faulkner 1999), has meant that other approaches have been rather neglected in the UK. As part of a re-investigation of the FEH methodology in a reservoir safety context (Stewart et al. 2009), it was therefore considered necessary to review the literature regarding other methods.

In Great Britain, reservoirs are classified into four categories depending on the potential risk to communities downstream in the event of a dam failure (ICE 1996). The reservoir design flood inflow for the highest category, Category A, is the probable maximum flood (PMF), with the lower categories B-D having design flow return periods between 10,000 and 150 years. It is these types of return periods that are the main focus of the review, although not all countries provide estimates of such high return periods. When river flow records are not available, or in addition to direct flood frequency estimation, flows can be estimated from rainfall records using a hydrological model. The latter approach results in an entire flow hydrograph which is required, for example, for reservoir design. A simple design rainfall may consist of an estimate of the total event rainfall and an associated temporal distribution, assuming a spatially uniform distribution over the catchment. The areal rainfall amount is related to the point rainfall amount via a so-called areal reduction factor (for a review of these see Svensson and Jones (2010)).

The rainfall return periods used for reservoir design require extrapolation of the quantile function well beyond the length of the observed individual rain gauge records. Methods to gain information for carrying out such extrapolation include

1) meteorological guidance

2) statistical extreme value theory

3) increasing the amount of data used for analysis:

a. using more events per year than the annual maxima approach

b. spatial data pooling

The first of these methods mainly concerns the estimation of probable maximum precipitation (PMP), whereas the last two are the bases for the methods described in this review. The extrapolation is not trivial. Vit Klemeš has outlined the problems associated with estimating the probabilities of extreme hydrological events in a number of papers (e.g. Klemeš 1986, 1988, 1989, 1993). His main point was that the hydrological information content of the data has been neglected in the pursuit of high mathematical rigour in the fitting of probability distribution models to the observed events. Among other things, he noted that extremes occur more due to unusual combinations of the physical factors contributing to the rainfall than to unusual magnitudes of the factors themselves, and therefore advocated a joint probability approach based on the same components as used for some PMP assessments (Klemeš 1993). In this way, the quantile estimate of each contributing factor does not require extrapolation, while the combination of the factors results in a rainfall of low 
probability. Eagleson (1972) outlined a similar approach for flood estimation, and joint probability methodologies for hydrological applications are being explored in several countries (e.g. Arnaud and Lavabre 2002, Rahman et al. 2002, Kjeldsen et al. 2010). Unless there are strong reasons to adopt a simple model (such as statistical independence), a joint probability methodology, because of the difficulties of modelling and estimating this dependence based on limited data, may not actually be an improvement over simpler methods.

Below, methods for point rainfall frequency estimation used nationwide in nine different countries are described country by country. The FSR and FEH methods are described in some detail, particularly in relation to issues where they have come in for some criticism. The review ends with a summary table of the methods and a discussion of the advantages and disadvantages of the different approaches used.

\section{Canada}

Environment Canada is the only source of Intensity-Duration-Frequency (IDF) information on a national scale for Canada, although many universities, provinces, municipalities and other agencies do similar research for their own applications (Robert Morris, Environment Canada, personal communication, August 2009). Up-todate IDF tables and graphs are available for 549 individual locations across Canada, downloadable from Environment Canada's webpage (EC 2010). As well as the IDF information, 50\% confidence limits around the rainfall estimates are provided for a selection of return periods $(2,5,10,25,50$ and 100 years) and durations (5, 10, 15, 30 minutes, and 1, 2, 6, 12 and 24 hours).

Derivation of the frequency curves, described by Hogg et al. (1989), is the same as for the earlier Rainfall Frequency Atlas for Canada (Hogg and Carr 1985). Whereas the up-to-date IDF information on the webpage involves users making their own spatial interpolation, this atlas contains maps of parameters for calculating estimates of rainfall at a particular return period for any location in Canada. Maps are available for rainfall durations between 5 minutes and 24 hours, making the estimates suitable for small or urban catchments. Estimates for longer durations are available on request.

The parameters used for the frequency estimation are the mean, $\mu$, and standard deviation, $\sigma$, of the annual maximum (AM) rainfall series, estimated using the method of moments. A rainfall estimate for a given return period is derived from a frequency-factor formulation of the Gumbel distribution, which involves these two parameters.

Hogg and Carr (1985) give maps of isolines of the mean and the standard deviation, and the user interpolates between these to obtain values for the location of interest. Logarithmic interpolation of estimates is recommended to obtain rainfall estimates for intermediate durations. An adjustment upwards is made to rainfall estimates in mountainous areas, with different factors for onshore coastal and non-coastal mountains. The adjustment factors increase with increasing duration. Precipitation extremes during the cold season (rainfall plus snowmelt) are dealt with separately. 
The values of mean and standard deviation can also be used to get a gross estimate of PMP. According to Hershfield (1977), PMP can be estimated using a version of this approach in which the frequency-factor changes with the mean and duration. These relationships were constructed by combining information from multiple gauges across several countries. Hogg and Carr (1985) quote these equations for durations of 1, 6 and 24 hours and note that such PMP estimates have been exceeded on several occasions.

\section{Sweden}

High-hazard dams in Sweden are designed using a deterministic approach, similar to the PMF procedure, with emphasis on critical timing of flood-generating factors. They are, however, not based on PMP estimates, but on observed maximum areal precipitation in combination with extreme snowmelt simulations: a trial and error procedure finds the worst flood for a specific river system. A nationwide study was undertaken of 24-h (2-day before 1926) $1,000 \mathrm{~km}^{2}$ and $10,000 \mathrm{~km}^{2}$ areal precipitation amounts exceeding $90 \mathrm{~mm}$ and/or $70 \mathrm{~mm}$, respectively, during the period 1881-1988. These 70 events formed the basis of five 14-day time-sequences of rainfall, appropriate for larger rivers. Each sequence is specific to one of five climatological regions, and was developed so that it roughly contains the largest observed amounts over 24 hours to 14 days duration. The precipitation sequences were arranged to generate the most critical flood development, which led to the largest 24-h value being located on day 9 of the sequence. Each precipitation sequence is corrected for season, catchment area and elevation before being entered into a hydrological model (Norstedt et al. 1992). The regionalisation is based on the magnitude of the extreme areal precipitation events (Flödeskommittén 1990). Alexandersson et al. (2001) report that the areal precipitation database is updated regularly.

Vedin and Eriksson (1988) give a rough empirical estimate of the return period, $T_{\text {areal, }}$, of the largest observed areal precipitation value in each homogeneous region as

$$
T_{\text {areal }}=N \cdot \frac{\text { area of region }}{\text { area of precipitation }},
$$

where the study period is $N$ years.

Taking into account the design values of rainfall used above, soil moisture deficits and snowmelt, Bergström et al. (1989) report that the resulting floods are expected to exceed a return period of 10,000 years.

A reinvestigation of the method (Bergström et al. 2008) concluded that most of the conditions prescribed in the guidelines have been relatively stable over the period that has elapsed since they were adopted. However, the frequency of occurrence of observed extreme areal rainfall events has increased, although there is at present no corresponding increase in observed runoff. Dahlström (2006) argues that, although quantitative information from climate simulations and trend analyses are uncertain, it may still be preferable to correct the design guidelines for potential increases to extreme rainfalls. 
Of probabilistic rather than deterministic methods, the station-year method for rainfall frequency analysis has been applied to an area straddling the border between Norway and Sweden (Alexandersson et al. 2001). When applying this method, all the data in a region are pooled into one long series, and analysed as if it were a single long record. Rainfall observations are assumed to be independent and identically distributed (e.g. Buishand, 1984). In this case, the combined dataset comprises about 2,300 stationyears derived from the AM precipitation series at each site, based on daily observations in the period 1961-2000. The region is considered homogeneous with respect to large daily rainfalls. Return periods were estimated both empirically and by fitting probability distributions. For example, there are six values greater than 100 $\mathrm{mm}$, and the empirical return period is therefore estimated to be $2,300 / 6=380$ years. The empirical return periods agree reasonably well with those estimated from a Generalised Extreme Value (GEV) distribution using probability-weighted moments (PWMs). The Gumbel distribution does not fit the upper tail of the data, either when fitted using the method of (product) moments, or when fitted using a regression on plotting positions. This lack of fit suggests that a three-parameter probability distribution like the GEV may be more appropriate.

For point precipitation of moderate return periods it is more common to fit GEV and Gumbel distributions to individual series rather than using the station-year approach (Lennart Wern, SMHI, personal communication, August 2009). If the time series of data is relatively short, the preferred method is to fit a GEV using an average of the shape parameter across nearby series. GEV and Gumbel fits are plotted for single sites, and subjective common sense is used when deciding which fit to use. Wherever possible, data from nearby stations are used, and it is noted that long series are needed to obtain a realistic fit of the GEV to individual series.

Precipitation estimates for sub-daily durations with return periods up to 10 years can be obtained through an equation using monthly mean precipitation for May, July and August as input (Dahlström 1979, summarised by Dahlström 2006).

\section{France}

Météo-France supplies rainfall estimates for return periods up to 100 years, for durations from 6 minutes to 10 days (Météo-France 2007; Météo-France 2010). Both $\mathrm{AM}$ and peak-over-threshold (POT) methods are used to estimate the frequency of short duration rainfalls. GEV distributions are used for the AM series, fitted using PWMs. The shape parameter $k$ is generally negative for rainfall durations between 1 and 24 hours, suggesting that a Gumbel distribution is not applicable. The so-called "renewal method" is a type of POT method, developed to be particularly suitable for short series (at least 10 years long). Starting using a low threshold yielding more than one independent event per year on average, a Generalised Pareto distribution is fitted to the peaks. Poisson or Negative Binomial distributions are fitted to the series of number of peaks in each year. The goodness-of-fit is assessed using $\chi^{2}$-tests for the distributions of exceedances and counts, and the significance levels are retained. The threshold is then successively increased, and new goodness-of-fit tests carried out, until there is only one value per year on average. The parameters of the sample that has the best fit are adopted for use if the significance level is better than 5\%. 
For high return periods, the GRADEX method (FRCOLD 1994) is used. It is a method for flood frequency estimation used for design of reservoirs, and includes analysis of rainfall data. Annual precipitation extremes (either point or areal values) are estimated for return periods between 10 and 10,000 years using the Gumbel distribution. The method gets its name from the "gradex", the parameter $a$, which is the slope of the frequency curve (a straight line) when plotted on the Gumbel scale. Rainfall estimates are obtained through a seasonal analysis. Firstly, for homogeneous seasons (weather-wise), the distribution function $\mathrm{FS}(P)$ of extreme precipitation is obtained from the frequency distribution $\mathrm{F}(P)$ of all (zero and non-zero) time-unit precipitations historically recorded in that season, as $\mathrm{FS}(P)=[\mathrm{F}(P)]^{m}$, where $m$ is the number of time-units in the season. This is justified by the poor autocorrelation between successive storms of more than 4 hours duration. Secondly, the distribution functions for the seasonal rainfall maxima can be multiplied to obtain the distribution function for the AM rainfalls. The requirement stated for this method is a few dozen of years of record. Because daily data are more abundant than sub-daily records, Kieffer and Bois (1997) investigated relating the gradex of 24-h rainfalls with observations of shorter duration. They conclude that a relationship can be established with 6-h and 12-h rainfalls, but not for shorter durations.

\section{Germany}

Design rainfalls in Germany are derived using three different methods depending on the target return period (DWD 2005). For 0.5 to 100 years return period, the KOSTRA method is used to estimate heavy precipitation (Bartels et al. 1997). The contribution from snowmelt is also considered, separately. At the top end of the return period scale, PMP is estimated, and in between the lower and upper ends an extrapolation of the KOSTRA method is used. The account below is based on Bartels et al. (1997) and personal communication with Gabriele Malitz at Deutscher Wetterdienst (July 2009).

The KOSTRA method estimates design rainfalls for durations between 5 minutes and 72 hours. The results are presented on a grid covering Germany, at a resolution of $8.45 \mathrm{~km}$. The gridded values are based on 5 minute resolution measurements for about 200 stations (records around 30 years long) and daily values at about 4500 stations (records often 60 years long). Precipitation is estimated separately for summer, winter and annually.

Both AM and POT series are used for the statistical analysis. Gumbel distributions are fitted to AM series and exponential distributions to POT series. The distributions are fitted by assigning plotting positions, $T$, (different for the two different distributions) to the observations and then fitting a regression line to the rainfall depth versus $\ln T$. The regression equation, in the case that an exponential distribution is fitted, is

$h(D, T)=u(D)+w(D) \ln T$,

where $h$ is the precipitation depth, $D$ is the duration, $T$ is the return period, and $u$ and $w$ are distribution parameters. For reasonably large return periods, this is an approximation to the Gumbel distribution. 
A regionalisation method is used to obtain precipitation estimates on the $8.45 \mathrm{~km}$ grid. In winter, precipitation events are predominantly advective, meaning that short- and long-duration precipitation amounts are more strongly related than in other seasons. Hence, the dense daily rain gauge network can provide information about sub-daily precipitation characteristics. The spatial dependence is also stronger in winter than in summer, making a distance-only spatial interpolation viable. In summer, heavy shortduration precipitation ( $\leq 60$ minutes) is mainly of small-scale convective origin, and does not show a good relationship with the precipitation characteristics for longer durations. However, there is a good relationship with orography, and the gradient and orientation of the slope of the terrain to the prevailing weather system are taken into account for the spatial interpolation. To obtain realistic precipitation amounts for all durations, the parameters $u(D)$ and $w(D)$ are smoothed across the durations.

KOSTRA precipitation estimates up to 100 years return period have been applied in the design of channel networks and water retention basins. For reservoir safety applications, with return periods above 100 years, the KOSTRA rainfalls are estimated using an extrapolation of the KOSTRA regression line, but using a steeper slope.

\section{United States}

The Hydrometeorological Design Studies Center (HDSC) within the Office of Hydrologic Development of National Oceanic and Atmospheric Administration's (NOAA) National Weather Service (NWS) is updating precipitation frequency estimates for various parts of the United States and affiliated territories (e.g. Perica et al. 2009). Updated precipitation frequency estimates for durations from 5 minutes to 60 days and selected return periods (1-year to 1,000-years) accompanied by additional information (e.g., 90\% confidence intervals, temporal distributions, seasonality) are published in NOAA Atlas 14 (NOAA 2010).

\section{The index-flood approach}

Precipitation frequency estimates are based on the analysis of AM series using an index-flood approach (e.g. Stedinger et al. 1993). The distribution of floods (or rainfall) at different sites in a region are assumed to be the same except for a scaling factor, the index. The problem is reduced to estimating the index for a site, and a standardised regional growth curve (the ratio of the quantiles to the index). Rainfall estimates at any site are then obtained by multiplying the site index value with the regionally derived growth curve.

\section{The index variable}

The index variable in this case is the mean AM rainfall. The means for each station and duration were spatially interpolated using PRISM technology (Daly et al. 1997; 2002) to produce index grids. For the Hawaian Islands (Perica et al. 2009), the spatial resolution is 15 arc seconds (about $400 \mathrm{~m}$ ), but recent work include resolutions down to 2.5 arc seconds (Sanja Perica, HDSC, personal communication, October 2009). 


\section{The growth curve}

Following Hosking and Wallis (1997), the growth curve is estimated using Lmoments. AM based frequency estimates are converted to POT based estimates using an empirical formula. This is useful for shorter return periods where these estimates differ.

The regionalisation involved an initial division into potential (fixed boundary) regions using cluster analysis based on topography and climatology of extreme events. Homogeneity and discordancy tests were carried out and necessary adjustments made to obtain the final regions. A variety of probability distributions (including GEV, Generalised Normal, Generalised Pareto, Generalised Logistic, Pearson Type 3, Kappa and Wakeby) were examined and the most appropriate distribution for each region and duration was selected using several different performance measures. The final determination of the appropriate distributions for each region and duration was made based on sensitivity tests and a desire for a relatively smooth transition between distributions from region to region.

Quantiles were determined based on the site index and the regionally determined Lmoments (weighted according to record length) of the selected probability distribution. Constant second and higher order moments within each region could result in the potential for discontinuities in the quantile estimates at regional boundaries. A spatial interpolation technique termed the Cascade, Residual Add-Back (e.g., Perica et al. 2009) that accommodates spatial smoothing and interpolation across regional boundaries was used to produce grids of precipitation estimates for various frequencies and durations. Monte Carlo simulation was used to provide $90 \%$ confidence intervals.

\section{South Africa}

The South African method for design rainfall estimation covers return periods between 2 and 200 years, and durations from 5 minutes to 7 days. It is referred to as RLMA\&SI, the Regional L-Moment Algorithm in conjunction with a Scale Invariance approach (Smithers and Schulze 2003; 2004). This is a regional frequency analysis method. Similar to the method used in the United States, it is based on Hosking and Wallis (1997) and uses L-moments and homogeneous regions for an index-flood approach. Rainfall estimates are available on a grid that covers the country with a spatial resolution of 1 arc minute.

\section{The index variable}

The index variable is the mean AM rainfall. The means can be estimated for any location using multiple linear regression relationships with site characteristics (mean annual precipitation, latitude and altitude). The exact formulation of the regression equations differ (i.e. selection of variables and fitted coefficients) for each homogeneous region. Different regions were used for different durations; seven 
regions for durations of 1 day or more, and 15 regions for durations of 24 hours or less. The regions were derived using cluster analysis of site characteristics (latitude, longitude, altitude, a monthly index of precipitation concentration, mean annual precipitation, a seasonality index and distance from the sea). By clustering according to site characteristics rather than on the rainfall statistics directly, the heterogeneity of each region can subsequently be assessed by comparing the between-site variability of L-moments with that which would be expected for a homogeneous region. The regions have fixed boundaries in the sense that the member stations in each region do not change with the target location for the frequency analysis, as in the methods used in e.g. New Zealand, Australia and the UK.

Strong linear relationships occur within each region when plotting each station's mean 1-day AM rainfall versus the same station's mean AM of a duration greater than 1 day. Similarly, the mean for durations $<24 \mathrm{~h}$ scale nearly linearly as a function of the 24-h values (the moving-window 24-h value is related to the fixed 1-day value at the site). The slope and intercept of these regression lines were found to scale by a power law relationship with duration. However, there were sometimes changes in the scaling, typically occurring at certain "pivotal" durations: 15 minutes, 2 hours, 1 day and 3 days. At ungauged sites, the means of the AM series were therefore estimated for the pivotal durations using regression on site characteristics, and those for intermediate durations were calculated from these values using the scaling relationships. Sub-daily estimates are thought to have been improved by the use of scaling based on daily observations. The daily records used are both longer and more abundant (1789 stations with at least 40 years of record) than sub-daily records (172 stations with at least 10 years of record).

\section{The growth curve}

The GEV distribution was deemed the most suitable for rainfall in South Africa. Growth curves were derived separately for each homogeneous region, using regionally averaged L-moment ratios, weighted in proportion to the sites' record lengths. The 1-day L-moment ratios generally fell within the $90 \%$ confidence intervals computed for other durations (from 30 minutes to 7 days) using a bootstrapping technique. Two other techniques also gave similar results. It was therefore concluded that design rainfall estimates for all durations may be estimated as the product of the 1-day growth curve and an estimate of the mean of the AM series for the duration in question. The preference for using the 1-day growth curve, rather than growth curves derived for each duration, is again based on the perceived greater reliability of the daily rainfall records than of records of other durations (particularly sub-daily records). For details of issues with the short-duration data, see Smithers and Schulze (2000).

\section{New Zealand}

The National Institute of Water \& Atmospheric Research (NIWA) maintains the national climate database for New Zealand, and NIWA's National Climate Centre (NIWA 2010) carries out climate mapping and analysis of high intensity rainfalls. Design rainfalls are estimated using the High Intensity Rainfall Design System 
(HIRDS) software (Thompson 1992). It was first developed in 1992, based on an established method for rainfall frequency estimation. It has been updated more recently regarding the regionalisation techniques used, and to include more up-to-date data (Thompson 2002). The HIRDS method uses an index-flood procedure to provide rainfall estimates of durations from 10 minutes to 72 hours, and return periods from 2 to 150 years.

\section{The index variable}

The index rainfall was taken to be the median AM rainfall. The sample median is used in preference to the mean, or some other location parameter, since it is not usually affected by the presence of outliers. The median rainfall was mapped by fitting thinplate smoothing splines as implemented by ANUSPLIN (Hutchinson 1995; 2000). The spline is a surface that is fitted to spatially distributed data with some error assumed at each data point, so that the surface can be smoother than if the data fitted exactly. Longitude, latitude and altitude above sea level were taken into account when fitting the spline. This trivariate spline of rainfall allows for a continuous spatially varying dependence on elevation, and is well suited to applications over complex terrain as is found in New Zealand. It can also be a robust method for moderately sparse data networks.

\section{The growth curve}

A "region of influence" approach (Burn 1990) is used to obtain a regional growth curve, rather than treating all of New Zealand as a single region. This means that a separate region is defined for each site of interest, thus avoiding boundary problems associated with fixed regions. Each site is assumed to be surrounded by stations having similar statistical attributes to the site of interest. The region of influence was selected isotropically, to include all stations within a $60 \mathrm{~km}$ radius. The limit is a compromise between the possibility of selecting stations from a different rainfall climate and the inclusion of too few stations to obtain a reliable estimate.

The GEV distribution is used to derive the growth curves. The parameters for the regional GEV are estimated through the method of regionally averaged standardised PWMs (Hosking et al. 1985; Cunane 1989), using weights in proportion to the record lengths.

For large parts of New Zealand the regional shape parameter $k$ is negative. There is a general increase in $k$ with increasing duration, with the GEV being close to a Gumbel distribution (i.e. $k=0$ ) for durations of 6 hours and longer.

The AM series at a site was used if each annual value came from a year with at least 11 months of data, and if there were at least 10 years of record (5 years for the estimation of the median rainfall in mountainous areas).

A new version of HIRDS should be available shortly (Graeme Horrell, NIWA, personal communication, May 2010). It will use the same underlying procedures, but 
will be based on a few more years of data. In addition, it will include an assessment module for climate change.

\begin{abstract}
Australia
In Australia, design rainfalls are derived in three different ways depending on their severity (Weinmann et al. 1999). At the extreme end, design floods for dam design are based on estimates of PMP, whereas at the lower end rainfall amounts are estimated using frequency analysis. The remaining gap in the frequency curve is filled by a pragmatic interpolation procedure. The methods for rainfall frequency estimation have recently been revised to extend the range of return periods for which the method is applicable. The new CRC-FORGE (Cooperative Research Centre - FOcussed Rainfall Growth Estimation) methodology is considered suitable for return periods from 50 up to 2000 years, and was developed using daily data (1-5 days). Procedures for estimating rainfalls down to 6 hours duration are available. CRC-FORGE is based on the FORGE method, which was developed at the Institute of Hydrology in the UK (Reed and Stewart 1989).
\end{abstract}

\title{
The index variable
}

The CRC-FORGE method (Weinmann et al., 1999) is an index-flood method where the index variable is the 50-year return period rainfall from a fitted Log-Pearson Type 3 distribution. This choice is based on a desire to make the higher return period rainfall estimates seamlessly continuous with the estimates previously obtained from the Australian Rainfall and Runoff (ARR 1987; reprinted 2001) method. This earlier method has its upper limit at the 1 in 100-year rainfall and is still the design practice for return periods up to 50 years, providing estimates for durations between 5 minutes and 72 hours. Weinmann et al. (1999) note that there is a strong and complex spatial variation in the index variable, making spatial interpolation difficult and subject to considerable error. Altitude explains part of the local variation, but other hydrometeorological factors are also involved.

\section{Search region}

Similarly to the HIRDS method used in New Zealand, the CRC-FORGE method uses a circular search area around the site of interest to define the region used for deriving the regional growth curve for the site. However, the circular regions expand around the site of interest (Figure 1), with each progressively larger region used to estimate sections of the growth curve corresponding to greater and greater return periods. The part of the growth curve corresponding to the smallest return periods is derived using only the rainfall data at the site of interest. The sizes of the circles are determined so that successive regions contain 3, 6, 12, 24, 48, 96 and 192 stations. Only the six highest ranking observations in each region are used to define the corresponding growth curve segment. 

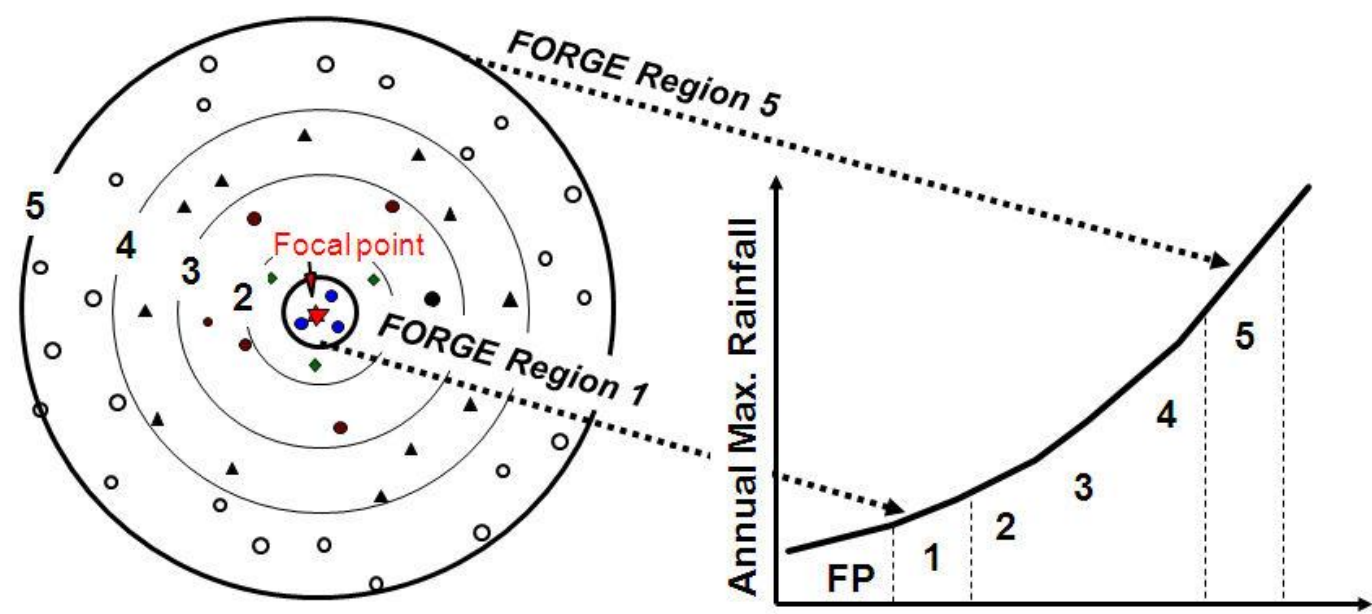

AEP

Figure 1. Expanding circular regions and corresponding frequency curve segments for different annual exceedance probabilities (AEP) (from Weinmann et al. (1999). This Figure was first published by The Institution of Engineers, Australia. It is reprinted here with permission).

\section{Fitting the growth curve}

A variant of the station-year method is used for estimating the growth curve: all the standardised AM for the stations in the region are pooled into one long series. Standardisation is achieved by division by the site's index variable. A large sample is thus created, making up for the limited record length. A spatial dependence model is applied to account for the reduction in useful information resulting from inter-site dependence in the pooled data. The six highest ranking standardised observations from each region are assigned return periods $T$ using the Gringorten plotting positions:

$1 / T=\frac{m-0.44}{L_{e}+0.12}$

where $m$ is the rank of the observation, and $L_{e}$ is the effective record length estimated using the dependence model (see next section). A GEV distribution is then fitted to the data points using a least squares fitting method (Nandakumar et al. 1997).

\section{The station-year method and the dependence model}

The traditional station-year method for regional frequency analysis involves pooling all the data into one long data series, and proceding under the assumption that the observations at the stations are independent of each other. An extreme value distribution can then be fitted to this one long series of length $L=N \bar{n}$, where $N$ is the number of stations in the region and $\bar{n}$ is their average record length. However, 
rainfall data from sites within a region generally exhibit some degree of inter-station dependence (or spatial correlation). The effective size of the regional sample is thus $L_{e}=N_{e} \times \bar{n} \leq L$, where $N_{e}$ represents the effective number of independent gauging stations in the region. In CRC-FORGE the estimate of $N_{e}$ for each region is assessed by fitting a spatial dependence model to the data (Weinmann et al. 1999; Nandakumar et al. 2000).

The relative information content of a regional data set of $\mathrm{N}$ stations can be expressed by the ratio $\ln N_{e} / \ln N$. This ratio varies with the degree of correlation, $\rho$, between the rainfall observed at different sites in the region, from 1 for independent data ( $\rho=0$, $N_{e}=N$ ) to a value of 0 for fully dependent data ( $\left.\rho=1, N_{e}=1\right)$. Simulation studies using long series of generated rainfall data indicated that the ratio of $\ln N_{e} / \ln N$ is not constant over the range of return periods, but tends to increase with increasing return period, approaching the value of 1 for very high return periods. This is in accordance with the intuitive expectation that the largest AM rainfall observations in a region are less dependent than more frequent events. Therefore a dependence model that varies with return period was used:

$$
\frac{\ln N_{e}}{\ln N}=\left\{\begin{array}{cc}
1-\alpha[y-\beta \ln (\bar{\rho} \ln N)-\gamma]^{2}, & \text { for } y \leq \beta \ln (\bar{\rho} \ln N)+\gamma, \\
1, & \text { otherwise },
\end{array}\right.
$$

where $y$, the Gumbel reduced variate, is an expression of the return period. The model parameters $\alpha, \beta$ and $\gamma$ depend on the rainfall duration $D$, and are fitted to the rainfall data from an overall homogeneous region (i.e. not the circular search region), and $\bar{\rho}$ is the mean correlation of the observed AM rainfall series at all pairs of stations in the region.

\section{Homogeneous regions for the spatial dependence model}

For the purpose of the dependence model, large areas that cannot be considered statistically homogeneous are separated into different regions. For example, Western Australia is divided into several regions based on meteorological and physical distinctions (Durrant and Bowman 2004). The regions were the same for all rainfall durations, but a seasonal analysis was also carried out and different regions were used for summer and winter. Thus, the regions used for the derivation of the dependence models have fixed boundaries. However, the procedure for determining the growth curve includes stations from adjoining regions to reduce any discontinuity across the region boundaries.

\section{Interpolation between frequency estimates and PMP}

A generalised procedure to fill the "gap" in the frequency curve, between the 2000 year return period rainfall and the PMP estimate, was developed by Siriwardena and Weinmann (1998) on the basis of work by Lowing and Law (1995) for floods in the UK. A 2-parameter parabolic function is fitted in log-log space to satisfy requirements at either end of the curve. The slope of the curve is not constrained in approaching the 
PMP. The PMP is assigned a return period of between 10,000 and 10,000,000 years, depending on the size of the catchment.

The frequency curves were shown to be plausible and well behaved for catchments of diverse characteristics, and to be consistent over a practically significant range of storm durations (Siriwardena and Weinmann 1998).

\section{United Kingdom: 1) Flood Studies Report}

The Flood Studies Report (FSR) method (NERC 1975) is not the most recently developed rainfall frequency estimation method for the United Kingdom, but it is still the standard for rainfalls of 1000 years return period or rarer. The method involves the mapping of an index variable, the 5-year return period rainfall, and derivation of regional growth curves applicable to durations from 15 seconds to 25 days. Two regions are used for the UK: England and Wales, and Scotland and Northern Ireland, but within each region there are different growth curves depending on the magnitude of the index variable.

\section{The index variable}

The 5-year return period rainfall, M5, for durations of 2 and 25 days was estimated using a quartile analysis (outlined below) of the ordered AM rainfall series. In effect, M5 was estimated as the geometric mean of the upper half of the AM rainfall series for each site. M5 for intermediate durations are obtained through interpolation in log space. M5 values were also estimated for durations down to 1 minute using various relationships.

\section{The growth curve}

The standardised growth curves were derived from non-standardised rainfall frequency curves for the two regions. Initially, frequency curves were fitted graphically using the results of quartile analyses of the AM rainfall series, as described in the next section. When the logarithm of the rainfall was plotted against the Gumbel reduced variate, the frequency curve was linear above a return period of 5 years, with the slope of the curve decreasing with increasing M5 rainfall amounts in a systematic manner regardless of duration. Dimensionless growth curves were derived by dividing the frequency curves by the M5 rainfall. Hence, the growth curves are different for different values of M5 within the same region, but are the same for different durations providing these have the same M5 value. Growth factors (points on the growth curve) are presented in tables for M5 varying from 0.5 to $1000 \mathrm{~mm}$.

\section{Fitting a frequency curve using quartile analysis and highest observations}

If a series of $N$ annual rainfall maxima are arranged in ascending order, and plotted using plotting positions, a graphically fitted smooth frequency curve can be drawn. The FSR uses the plotting position suggested by Chegodayev (1953), 
$(m-0.31) /(N+0.38)$, where $m$ is the order of the maxima. However, the FSR also notes that summary statistics from a quartile analysis of (long) series can be used to fit a frequency curve, making it easier to combine many datasets into a comprehensive regional analysis.

The ordered series of AM are divided into four quarters, or quartiles. The geometric means of each quartile can be shown to correspond to particular return periods. For example, the highest quartile gives the 10-year rainfall. Two different ways of forming halves of the series are also considered. The geometric mean of the middle half (i.e. the middle two quartiles) corresponds to the 2-year rainfall (M2) and the geometric mean of the upper half corresponds to the 5-year rainfall (M5, which is used as the index variable).

The series are divided into classes depending on the magnitude of the M5 rainfall, and standardised using division by M5. Within each class, the medians (as defined in the FSR) of the standardised M2, M5 and M10 values across the stations in the class are plotted, together with some other information from the individual series. For high return periods the following approach is used. If the network of stations is not too dense, the largest (standardised) value from each series is put into a pooled dataset, which can then be plotted in a variant of the station-year approach to regionalisation. That is, the largest values are assumed to be the largest in a very long, pooled, time series (for example, 175 stations $\times 60$ years $=10,500$ station years for the class with 2-day M5 between 40 and $50 \mathrm{~mm}$ in England and Wales). Thus, points are plotted corresponding to return periods of several thousands of years.

\section{United Kingdom: 2) Flood Estimation Handbook}

The rainfall frequency estimation method of the Flood Estimation Handbook (FEH) is described by Faulkner (1999). It uses the FORGEX method for rainfall frequency estimation (Reed et al. 1999) followed by the fitting of a depth-duration-frequency (DDF) model. Values of the six parameters for the DDF model are available on a $1-\mathrm{km}$ grid on the FEH CD-ROM, together with software to provide design rainfall estimates for both individual points and catchment areas. FORGEX, which is a development of the FORGE method (Reed and Stewart 1989), is an index-flood method. For the growth curve, it pools data from expanding circular regions centred on the point of interest, or focal point. Because the regions vary only slightly between adjacent sites, the resulting growth curves vary relatively smoothly across the country.

Although the recommended upper limit of the FEH method is for rainfalls up to 2000 years return period (based on the range of return periods involved in the underlying data analyses), the software allows extrapolation to 10,000 years for pragmatic reasons. Since its release several papers have been written on the differences in results between the FEH and the FSR, mainly critisising the extrapolation in the FEH DDF model (using a log-Gumbel distribution and extrapolating beyond the return period that can be estimated from the data) and the fact that the dependence model assumed the dependence between rainfall at different sites to be constant rather than decreasing with increasing return period (e.g. Babtie Group 2000; MacDonald and Scott 2001; Clark 2002; Cox 2003). These issues resulted in the new FEH 10,000-year estimates being considerably larger than the previous FSR rainfalls, and not infrequently 
exceeding the FSR PMP estimates. Official guidance was therefore given to panel engineers (Defra 2010) that the FEH rainfall estimates should not entirely replace the old FSR estimates. Thus both methods have been the design standard for the UK since 1999, for different return periods: the FEH for the 193- and 150-year return periods (for use when estimating the 150-year flood event); the highest of the two methods for the 1000-year return period; and the FSR only for the 10,000-year return period.

Other potential problems are that possible effects of topographical variables on the growth curve are not taken into account (although they are for the index variable), and that some boundary effects due to the uneven spatial distribution of rain gauges with long rainfall records have been noted.

\section{The index variable}

The index variable is the median AM rainfall at the site, RMED. Values of RMED for eight rainfall durations between 1 hour and 8 days were estimated at stations with record lengths of at least 9 years. The estimates will still be susceptible to climatic fluctuations, but the chosen minimum record length is a compromise between having too short and too few series. RMED was mapped over the UK on a 1-km grid using georegression on topographical and other variables (Faulkner and Prudhomme 1998).

\section{The growth curve}

FORGEX pools data from a hierarchy of expanding circular regions centred on the point of interest (Figure 2). Data from smaller networks are used to estimate the growth curve for short return periods and data from the larger networks are used for the longer return periods. The size of a region is a compromise between keeping a region small, and therefore relevant, and avoiding excessive extrapolation beyond the information available in the region to obtain high return period rainfall estimates. An upper limit of $200 \mathrm{~km}$ is used for the largest network radius.

The derivation of the growth curve uses a complex empirical approach, combining a regional frequency analysis with an analysis of network maximum points whose plotting positions are shifted to allow for spatial dependence of extremes. Standardised AM (standardised through division by RMED) from individual records with a minimum length of 10 years are ranked and plotted on a Gumbel reduced variate scale using the Gringorten plotting position. Note that records are not pooled into one long series the way they are in the CRC-FORGE method. Instead, data for different sites are superposed on the plot (Figure 3).

Not all points are plotted, and only points which are plotted are used to fit the growth curve. Data from sites within progressively larger regions are used to estimate sections of the growth curve corresponding to greater and greater return periods. Thus, data points from within the $j$ th network are only plotted if their plotting position falls within the $j$ th section of the growth curve. Each section, or $y$-slice, has width 1.0 on the Gumbel reduced variate scale, starting at $y=0.3665$, which corresponds to the position of the median ( $T=2$ years). 


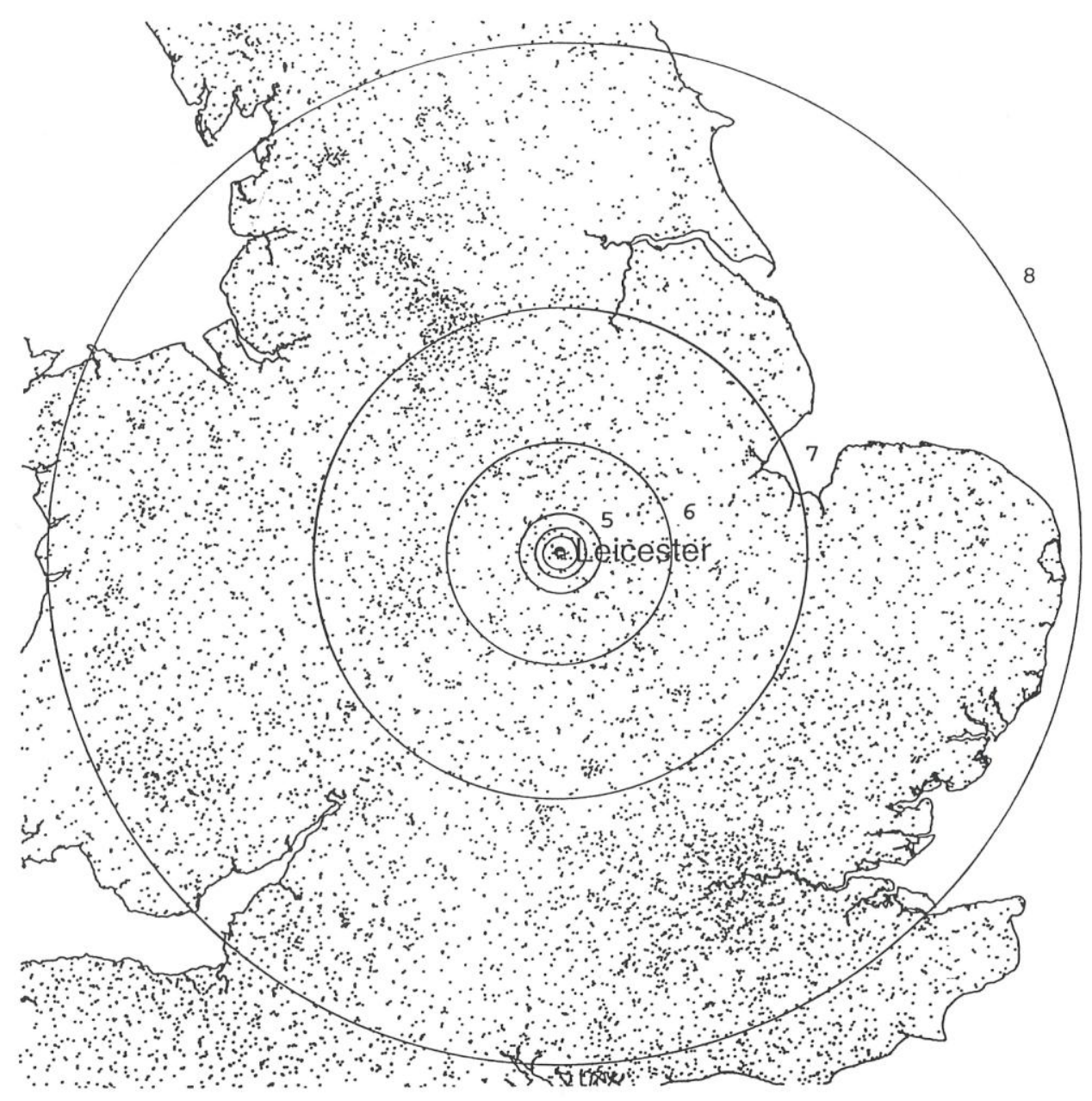

Figure 2. Networks (regions) of daily rain gauges focused on Leicester (from Faulkner (1999) (C) NERC (CEH)).

Two different groups of data series are recognised. Firstly, there are series of standardised values from individual stations. Because few stations have more than about 100 years of records, there are few points plotted at a return period larger than 200 years. Secondly, there are network maximum (netmax) series, defined as the AM series of the largest standardised value recorded anywhere within the region. Thus, there is one netmax value per year. Because of spatial dependence in the network of rain gauges, the plotting positions for the netmax points have been modified using a spatial dependence model (see next section).

For a given duration, an empirical growth curve consisting of concatenated linear segments is fitted to the plotted points (both individual and netmax) through a leastsquares routine. Finally, a depth-duration-frequency (DDF) model is fitted to avoid any contradictions between durations or return periods. This is an exponential curve on the Gumbel reduced variate scale, fitted to all durations (1, 2, 6, 12 hours, and 1, 2, 4,8 days) and return periods $(2,5,10,20,50,100,200,500,1000$ years) at once, using a least-squares criterion. 


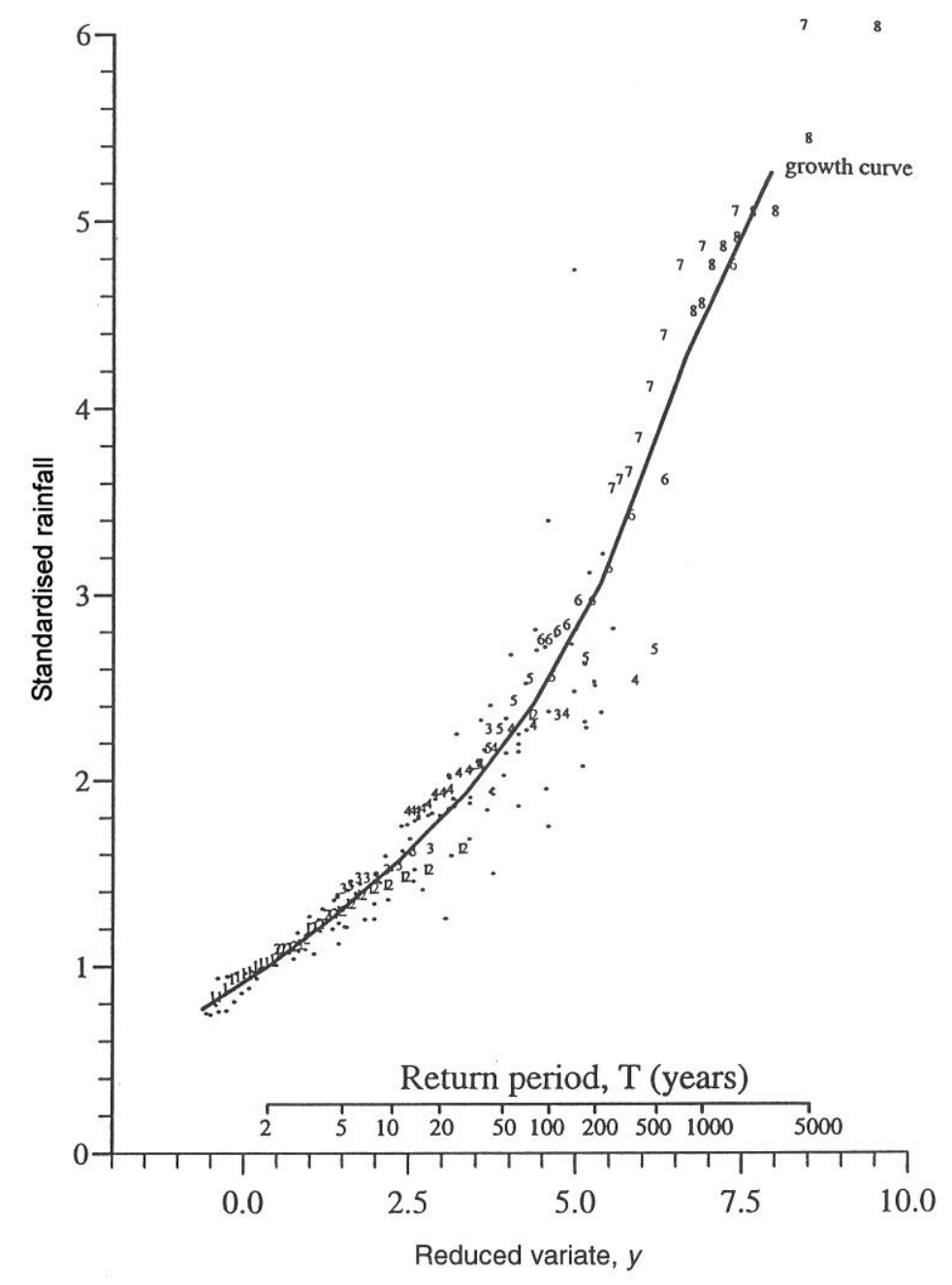

Figure 3. Individual points (dots), netmax points (numbers) and fitted empirical growth curve for 1-day rainfalls focused on Leicester (from Faulkner (1999) () NERC (CEH)).

\section{The spatial dependence model}

Dales and Reed (1989) show that the distribution of the network maximum from $N$ independent and identically distributed GEV distributions lies exactly $\ln N$ to the left of the regional growth curve (the "typical" growth curve for a station in the region) on a Gumbel reduced variate scale. Reed and Stewart (1994) note that this result is not restricted to the GEV. In practice, because of inter-site dependence in annual maxima, the netmax growth curve is found to lie a shorter distance to the left. Dales and Reed label this distance $\ln N_{e}$, terming $N_{e}$ the effective number of independent gauges. Thus, spatial dependence can be assessed from the relationship between the typical and network maximum growth curves. Conversely, the fitting of the regional growth curve can be aided by information on spatial dependence. In particular, if an estimate of $N_{e}$ is available, the top part of the netmax series can provide valuable information to guide the extension of the regional growth curve to long return periods. 
Dales and Reed (1989) developed a model of spatial dependence to estimate the offset distance, $\ln N_{e}$, for any rain gauge network. The UK model relates dependence to the geometry of the rain gauge network:

$\ln N_{e} / \ln N=0.081+0.085 \ln \mathrm{AREA}-0.051 \ln N-0.027 \ln D$

where $N$ is the number of gauges and $D$ the rainfall duration in days. AREA is a nominal area spanned by the network.

For each network in turn, the netmax series is constructed and the values ranked. If the same gauges were available for each year of record, the plotting position of each point would effectively include a shift to the right on the Gumbel reduced variate scale by $\ln N_{e}$. Because the number of operational rain gauges, $N$, has varied greatly over the past two centuries, a more complicated determination of the plotting positions is needed as described by Jones (1997).

\section{Discussion}

This review has outlined methods for rainfall estimation used nationwide in nine different countries. Although some of the individual components of the methods may be the same in several countries, the way they are combined in the final methods vary. A summary is provided in Table 1 . The advantages and disadvantages of the various choices of statistical distribution, fitting techniques, types of data, regionalisation, data pooling and spatial dependence are discussed below. For the index-flood approach, the choice of index variable and characteristics of the growth curves are also considered.

\section{Statistical distributions and fitting methods}

The parameters for statistical frequency distributions can be estimated using various methods. Product moments, such as the standard deviation, are sensitive to outliers in the data, and L-moment parameters are generally considered more robust (e.g. Stedinger et al. 1993). L-moments are linear combinations of the observations, and thus do not involve squaring or cubing the observed values as do product moments. PWMs are equivalent to L-moments (each set of moments are linear combinations of the other).

Other fitting methods include fitting a regression line, generally using a least-squares fit, to points plotted using plotting positions on an appropriate scale so that they ideally - form a straight line. Maximum likelihood estimators would not appear to be in use, possibly because the numerical calculations are time consuming and may not converge if the fit to the data is poor. Both these problems would be troublesome on a larger, national, scale compared with smaller studies. For the commonly used GEV distribution, L-moment estimators also compare favourably with those from maximum likelihood methods, particularly for small sample sizes (15-25 samples) (Hosking et al. 1985). 
In some countries a Gumbel distribution is used, partly because estimation of a shape parameter from short records is not justified for individual sites, but also to avoid the effect of outliers on the parameters. However, a distribution having more parameters (including a non-fixed shape parameter) may be necessary to obtain an adequate representation of the data. Rainfall extremes for at least some durations in parts of Scandinavia (Alexandersson et al. 2001), France (Météo-France 2007) and New Zealand (Thompson 2002) do not follow a Gumbel distribution. Shape parameters can be estimated with more confidence when a whole area displays the same characteristics, so that information can be transferred to estimate the distribution for a given site. Distributions with three (or more) parameters are therefore commonly used when sites have been regionalised into homogeneous zones, whereas the Gumbel is more suitable for single-site analysis. Most countries have one or two preferred statistical distributions, but the United States choose from a variety which, given that it is a large country with many different climates, makes it more likely that there will be a good fit to the regional data.

\section{Block maxima and POT data}

All countries surveyed use AM rainfall data, which are generally readily available and easy to extract. In addition, some countries like France and Germany use POT series (i.e. selecting a certain number of peaks on average each year) to increase the amount of data analysed, particularly when only short data series are available. There is some evidence that estimates of $T$-year events given by the POT approach have greater precision than estimates given by the annual maxima approach (e.g. Cunnane 1973, Madsen et al. 1997). Using a larger amount of data, including selecting a fixed number $(>1)$ of extremes in each year, should improve the rainfall frequency estimates. However, Buishand (1986) warns that although extending a sample with lower observations may reduce the standard error of the quantile estimates, it may lead to an increase in the systematic errors of the estimates of large quantiles: this relates to how representative the lower observations are of the extremes of the population.

Another way of retrieving extra information for the frequency analysis is to use block maxima from blocks that are smaller than a year, like a month or a season, and subsequently derive the annual rainfall distribution from these seasonal distributions. Dickinson (1977) argued that, by estimating the annual exceedance levels from monthly rather than annual maxima, the effect of anomalously high data points on the return level estimates is reduced. A similar effect should occur for division into two seasons, as in the French GRADEX method. When investigating ways of taking seasonality into account, Carter and Challenor (1981) found (for the UK) annual return levels estimated from monthly maxima to be larger than those estimated directly from annual maxima. However, Tabony (1983) argued that this may be because monthly maxima are drawn from too small a population (he estimated there would only be about 10 independent observations in a month for meteorological applications), and may not necessarily be extreme values. This problem would be smaller using seasonal maxima. 


\section{Regionalisation}

Most countries except France use some way of incorporating information from nearby sites when estimating the rainfall frequencies at a target point. Sweden, the United States and South Africa use regions with fixed boundaries, which mean that care needs to be taken to ensure a smooth transition of the rainfall estimates across the borders. The "region of influence" approaches used in New Zealand, Australia and the $\mathrm{UK}(\mathrm{FEH})$, for which the regions are centred on the site of interest, by design result in relatively smoothly changing rainfall estimates for nearby sites. Although the Canadian method does not include a regionalisation in the sense discussed above, the use of isolines when mapping the statistical parameters (in the older atlas of Hogg and Carr (1985)) means that there will be a certain amount of smoothing of the parameters. The German method applies spatial interpolation techniques to get rainfall estimates on a grid. These techniques are different for summer, winter and the whole year, enabling the seasonal characteristics of the precipitation to be represented.

The size of a region is a trade-off between how homogeneous it is and how much data it can provide for the regionalised frequency estimate. The FSR's (NERC 1975) division of the UK into only two regions - albeit with the growth curves varying with M5 - means that rainfall frequency estimates show little spatial variability, and a criticism of the method has been that it does not capture local anomalies well.

\section{Data pooling and spatial dependence}

Data from within each homogeneous region can be used in different ways for the regional analysis. For example, L-moment ratios or PWMs estimated for each individual standardised rainfall series can be averaged for the region and weighted by record length (United States, South Africa, New Zealand), or all the standardised annual maxima can be pooled together into a single long series in a station-year approach (Sweden, Australia) or network maxima approach (UK). Spatial dependence in rainfall observations affects all approaches. Hosking and Wallis (1997) used Monte Carlo simulations to investigate the effect of correlation between stations within a region on the growth curve derived using L-moments. They concluded that the resulting bias is small but that the variability of the regional growth curve increases with increasing correlation. Inter-site dependence thus acts similarly to a reduction in the number of sites in the region, and after a certain point, the addition of sites with observations at the same time points as the other sites merely duplicates information already obtained from the other sites. When investigating the application of the station-year method for an area in the Netherlands, Buishand (1984) estimated a dependence function for the annual maxima, and found that, except where the interstation distance is small, the data are effectively asymptotically independent. $\mathrm{He}$ concluded that for this area the station-year method can be applied to AM data provided that the stations are separated by at least $30 \mathrm{~km}$.

The Australian CRC-FORGE (Weinmann et al. 1999) and UK FEH (Faulkner 1999) methods both explicitly model the spatial dependence in the rainfall data and takes it into account for the analyses. However, whereas CRC-FORGE allows the dependence to decrease with increasing return period, the FEH assumes that the dependence is constant. It has been argued that this, together with the extrapolation method in the 
FEH DDF model (fitting a log-Gumbel distribution), is the reason why the FEH 10,000-year estimates are considerably larger than the previous FSR rainfalls, not infrequently exceeding the FSR PMP estimates (e.g. Babtie Group 2000; MacDonald and Scott 2001; Clark 2002; Cox 2003).

The use of a spatial dependence model enables attribution of a much higher return period to an observation than implied by the length of the individual rain gauge record. This confers a sense of increased confidence in the higher rainfall quantile estimates, but it should be borne in mind that spatial dependence may be more complex than currently allowed for in the models.

\section{The index variable}

The countries using an index-flood approach need to derive an index variable that is used for scaling the rainfall data so that the scaled values follow a common growth curve. Using the median of the AM rainfall series gives a more stable estimate than the mean, as it is less sensitive to outliers. Australia uses the 50-year return period rainfall to make the higher return period rainfall estimates seamlessly continuous with the estimates previously obtained from the Australian Rainfall and Runoff (ARR 1987; reprinted 2001) method. This could result in larger uncertainty compared with using the median or mean of the AM rainfall series.

\section{Growth curve}

The growth curve, a frequency curve for standardised rainfall, is used with indexflood methods and allows data from different locations to be pooled together. Most methods fit different growth curves to different durations, but Smithers and Schulze (2003) noticed for South Africa that the 1-day L-moment ratios generally fell within the $90 \%$ confidence intervals computed for other durations (from 30 minutes to 7 days). Hence, they use the same (1-day) growth curve for all durations. Provided that the value of the index variable increases with increasing duration at the same site, this should avoid the potential problem of frequency curves crossing at high return periods for different durations (i.e. it cannot rain more in, say, 1 hour than it does in 2 hours for the same return period). This is a simple and appealing approach, making use of reliable daily rainfall observations to improve the growth curve estimate for other durations with less reliable records. The approach can potentially be validated as increasingly longer records of short-duration data become available.

The FSR (NERC 1975) uses the same growth curve for all rainfalls with a particular M5 value, regardless of duration. This is an unusual feature, although it seems supported by the limited evidence presented in the FSR. At each location, the growth curve will still vary with duration (as is generally the case), as the M5 values increase with increasing duration. 


\section{Summary and conclusions}

The rainfall frequency estimation methods currently in use in nine different countries are described: Canada, Sweden, France, Germany, the United States, South Africa, New Zealand, Australia and the UK. There is considerable difficulty in estimating long return period rainfalls from short data records and there is no obviously "best" way of doing it. Each country's method is different, but most use some form of regionalisation to transfer information from surrounding sites to the target point. Several are variations of a regionalisation method that combines a local estimate of an index variable (typically the mean or median annual maximum rainfall) with a regionally-derived growth curve to obtain a design rainfall estimate. Regionalisation generally involves the delineation of homogeneous regions, selection of a regional probability distribution function, and parameter estimation. The boundaries of the regions can be fixed, or the regions can be centred on the point of interest so that the boundaries vary for each subject site. Three of the methods use site-centred rather than fixed-boundary regions. Different statistical distributions and fitting methods are used in different countries, with the GEV distribution being the most common.

There is a trade-off between the straightforwardness of a method and the size of the return period for which a rainfall can be reliably estimated: different countries use methods of different complexity. While regionalisation methods are attractive in allowing rainfalls for higher return periods to be estimated, caution is needed in regard both to the homogeneity of any region used and to the adequacy of the adjustment made, if any, for the effects of dependence. Diagnostic checking of the assumptions involved in either of these questions is typically not possible because of the shortness of the records available, which is the very reason for considering regionalisation.

\section{Acknowledgements}

This review was undertaken as part of the UK Defra-funded project "Reservoir Safety - Long Return Period Rainfall” (WS194/2/39).

The authors are much obliged to staff at the different hydrological and meteorological organisations who read and commented on the drafts describing each country's methods: Robert Morris at Environment Canada; Lennart Wern at the Swedish Meteorological and Hydrological Institute; Jean-Michel Veysseire at Météo-France; Gabriele Malitz at Deutscher Wetterdienst; Sanja Perica at the Hydrometeorological Design Studies Center within NOAA, US; Jeff Smithers at the University of Natal, South Africa; Craig Thompson and Graeme Horrell at the National Institute of Water and Atmospheric Research, New Zealand; and Erwin Weinmann at Monash University, Australia.

\section{References}

Alexandersson, H., Førland, E. J., Helminen, J., Sjöblom, N. and Tveito, O. E. (2001) Extreme value analysis in the Nordic countries - pilot studies of minimum 
temperature and maximum daily precipitation and a review of methods in use. DNMI - Report No. 03/01 KLIMA, Norwegian Meteorological Institute, Oslo, Norway, May 2001, 26 pp.

Arnaud, P. and Lavabre, J. (2002) Coupled rainfall model and discharge model for flood frequency estimation. Water Resour. Res., 38(6), article 11.1-11.11.

ARR (2001) Australian Rainfall and Runoff - a guide to flood estimation (two volumes). Engineers Australia, Barton, Australia.

Babtie Group in association with CEH Wallingford and Rodney Bridle Ltd (2000) Reservoir safety - Floods and reservoir safety: Clarification on the use of FEH and FSR design rainfalls. Final report to the Department of the Environment, Transport and the Regions (DETR). Babtie Group, Glasgow, UK, 36 pp.

Bartels, H., Malitz, G., Asmus, S., Albrecht, F. M., Dietzer, B., Günther, T. and Ertel, H., (1997) Starkniederschlagshöhen für Deutschland (KOSTRA-Atlas). Deutscher Wetterdienst, Offenbach, $82 \mathrm{pp}$.

Bergström, S., Hellström, S.-S., Lindström, G. and Wern, L. (2008) Follow-up of the Swedish guidelines for design flood determination for dams. Report No. 1:2008, BE90. Svenska Kraftnät, Vällingby, Sweden, 37 pp.

Bergström, S., Lindström, G. and Sanner, H. (1989) Proposed Swedish spillway design floods in relation to observations and frequency analysis. Nordic Hydrol., 20, 277-292.

Buishand, T. A. (1984). Bivariate extreme-value data and the station-year method. $J$. Hydrol., 69, 77-95.

Buishand, T. A. (1986) Extreme value analysis of climatological data. Proc. Third Int. Conf. on Statistical Climatology, Vienna, Austria, 23-27 June 1986, pp. 145-158.

Burn, D. H. (1990) Evaluation of regional flood frequency analysis with a region of influence approach. Water Resour. Res., 26, 2257-2265.

Carter, D.J.T. and Challenor, P.G. (1981) Estimating return values of environmental parameters. Quart. J. Royal Met. Soc., 107, 259-266.

Chegodayev, N. N. (1953) Computation of runoff on small catchments. Transzhedorizdat, Moscow.

Clark, C. (2002) Safety revisions. Internat. Water Power \& Dam Constr., 54, 18-26.

Cox, D. R. (2003) Some comments on 10,000 year return period rainfall. Report to Defra, UK. 24 pp.

Cunnane, C. (1973) A particular comparison of annual maxima and partial duration series methods of flood frequency prediction. J. Hydrol., 18, 257-271. 
Cunnane, C. (1989) Statistical distributions for flood frequency analysis. Operational Hydrology Report No 33. World Meteorological Organization, Geneva, Switzerland, $73 \mathrm{pp}$.

Dahlström, B. (1979) Regional fördelning av nederbördsintensitet - en klimatologisk analys. Rapport R18:1979, Byggforskningen, 33 pp.

Dahlström, B. (2006) Regnintensitet i Sverige - en klimatologisk analys. VA-Forsk rapport Nr 2006-26. Svenskt Vatten, Stockholm, Sweden, 69 pp.

Dales, M. Y. and Reed, D. W. (1989) Regional flood and storm hazard assessment. IH report No. 102. Institute of Hydrology, Wallingford, UK, 159 pp.

Daly, C., Gibson, W. P., Taylor, G. H. and Pasteris, P. (2002) A knowledge-based approach to the statistical mapping of climate. Climate Research, 23, 99-113.

Daly, C., Taylor, G. and Gibson, W. (1997) The PRISM approach to mapping precipitation and temperature. Proc. $10^{\text {th }}$ Conf. on Applied Climatology, American Meteorological Society, Reno, Nevada, 20-23 Oct. 1997. Pp. 10-12.

http://www.ocs.orst.edu/pub/prism/docs/appclim97-prismapproach-daly.pdf

Defra (2010) The document "Floods and Reservoir Safety (FEH/FSR) - Revised Guidance for Panel Engineers" is available on request via http://www.defra.gov.uk/environment/flooding/reservoir/safety.htm, accessed on 24 May 2010.

Dickinson, T. (1977) Rainfall intensity - frequency relationships from monthly extremes. J. Hydrol., 35, 137-145.

Durrant, J. and Bowman, S. (2004) Estimation of rare design rainfalls for Western Australia: Application of the CRC-FORGE method. Surface Water Hydrology Report Series, Report No. HY17, Department of Environment, Government of Western Australia, December 2004, 121 pp.

DWD (2005) Overview of extreme value statistics as a function of the reoccurrence interval in years (T). Slide presentation, Deutscher Wetterdienst (DWD) - Department of Hydrometeorology, 29 November 2005. Courtesy of Dr Rudolf Bruno, DWD.

EC (2010) http://www.climate.weatheroffice.ec.gc.ca/prods_servs/index_e.html, accessed on 24 May 2010.

Eagleson, P. S. (1972) Dynamics of flood frequency. Water Resour. Res., 8(4), 878898.

Faulkner, D. (1999) Flood Estimation Handbook, Vol. 2: Rainfall frequency estimation. Institute of Hydrology, Wallingford, UK, $110 \mathrm{pp}$.

Faulkner, D. S. and Prudhomme, C. (1998) Mapping an index of extreme rainfall across the UK. Hydrol. and Earth System Sci., 2, 183-194. 
Flödeskommittén (1990) Riktlinjer för bestämning av dimensionerande flöden för dammanläggningar. Slutrapport från Flödeskommittén (Statens Vattenfallsverk, Svenska Kraftverksföreningen, SMHI), Swedish Meteorological and Hydrological Institute, Norrköping, Sweden.

FRCOLD (1994) Design flood determination by the gradex method. French Committee on Large Dams (FRCOLD), November 1994.

Hershfield, D. M. (1977) Some tools for hydrometeorologists. Preprints, $2^{\text {nd }}$ Conf. Hydrometeorology, American Meteorological Society, Boston, Mass., pp 79-82.

Hogg, W. D. and Carr, D. A. (1985) Rainfall frequency atlas for Canada. Canadian Climate Programme, Canadian Government Publishing Centre, Supply and Services Canada, Ottawa, Canada.

Hogg, W. D., Carr, D. A. and Routledge, B. (1989) Rainfall intensity-duration frequency values for Canadian locations. Environment Canada, Atmospheric Environment Service, Downsview, Ontario.

Hosking, J. R. M. and Wallis, J. R. (1997) Regional frequency analysis, an approach based on L-moment. Cambridge University Press, 224 pp.

Hosking, J. R. M., Wallis, J. R. and Wood, E. F. (1985) Estimation of the generalized extreme-value distribution by the method of probability-weighted moments. Technometrics, 27(3), 251-261.

Hutchinson, M. F. (1995) Interpolating mean rainfall using thin plate smoothing splines. Int. J. Geographical Information Systems, 9, 385-403.

Hutchinson, M. F. (2000) ANUSPLIN Version 4.1 User Guide. Centre for Resource and Environmental Studies, The Australian National University, Canberra, Australia.

ICE (1996) Floods and reservoir safety, 3rd ed. Publ. by Thomas Telford for the Institution of Civil Engineers, London. 63 pp.

Jones, D. A. (1997) Plotting positions via maximum-likelihood for a non-standard situation. Hydrol. and Earth System Sci., 1, 357-366.

Kieffer, A. and Bois, P. (1997) Variability of the statistical characteristics of extreme rainfall values in the French Alps. Rev. Sci. Eau, 10(2), 199-216 (article in French).

Kjeldsen, T. R., Svensson, C. and Jones, D. (2010) A joint probability approach to flood estimation using Monte Carlo simulation. Proc. BHS Third Int. Symp. Role of hydrology in managing consequences of a changing global environment, Newcastle, 19-23 July 2010.

Klemeš, V. (1986) Dilettantism in hydrology: transition or destiny? Water Resour. Res., 22(9), 177S-188S.

Klemeš, V. (1988) A hydrological perspective. J. Hydrol., 100, 3-28. 
Klemeš, V. (1989) The improbable probabilities of extreme floods and droughts. In Starosolszky, Ö. and Melder, O. M. (eds) Hydrology of disasters. Proc. World Meteorological Organization Tech. Conf., Geneva, November 1988, pp. 43-51. James and James, London.

Klemeš, V. (1993) Probability of extreme hydrometeorological events - a different approach. In Extreme hydrological events: precipitation, floods and droughts, Proc. Yokohama Symp., July 1993. IAHS Publ. no. 213, pp. 167-176.

Lowing, M. J. and Law, F. M., (1995) Reconciling flood frequency curves with the Probable Maximum Flood. Proc. of the BHS 5th National Hydrology Symposium, Heriot-Watt University, Edinburgh, 4-7 September 1995.

MacDonald, D. E. and Scott, C. W. (2001) FEH vs FSR rainfall estimates: An explanation for the discrepancies identified for very rare events. Dams \& Reservoirs, 11, 280-283.

Madsen, H., Rasmussen, P. F. and Rosbjerg, D. (1997) Comparison of annual maximum series and partial duration series methods for modeling extreme hydrologic events: 1. At-site modeling. Water Resour. Res., 33(4), 747-757.

Météo-France (2007) "Fiche méthode durées de retour". Annex to CLIMATHÈQUE user manual, version 1.2. Direction de la Climatologie, Météo-France, Toulouse, France.

Météo-France (2010) http://climatheque.meteo.fr/okapi/accueil/okapiWeb/index.jsp, accessed on 24 May 2010.

Nandakumar, N., Weinmann, P. E., Mein, R. G. and Nathan, R. J. (1997) Estimation of extreme rainfalls for Victoria using the CRC-FORGE method (for rainfall durations 24 to 72 hours). Report 97/4, May 1997. Cooperative Research Centre for Catchment Hydrology, Monash University, Victoria, Australia, 118 pp.

Nandakumar, N., Weinmann, P. E., Mein, R. G. and Nathan, R. J. (2000) Estimation of spatial dependence for the CRC-FORGE method. Proc. Hydro 2000 - Interactive Hydrology, $3^{\text {rd }}$ Int. Hydrology \& Water Resources Symposium, Perth, 20-23 November 2000, Inst. of Eng. Australia, pp. 553-557.

NERC (1975) Flood Studies Report (five volumes). Natural Environment Research Council, UK.

NIWA (2010) http://www.niwa.co.nz/our-science/climate/our-services, accessed on 24 May 2010.

NOAA (2010) http://www.nws.noaa.gov/oh/hdsc/index.html, accessed on 24 May 2010. 
Norstedt, U., Brandesten, C.-O., Bergström, S. Harlin, J. and Lindström, G. (1992) Re-evaluation of hydrological dam safety in Sweden. Int. Water Power \& Dam Constr., 44(6), 43-49.

Perica, S., Martin, D., Lin, B., Parzybok, T., Riley, D., Yekta, M., Hiner, L., Chen, L.C., Brewer, D., Yan, F., Maitaria, K., Trypaluk, C. and Bonnin, G. M. (2009) NOAA Atlas 14, Volume 4, Version 2.1: Precipitation-Frequency Atlas of the United States, Hawaiian Islands. NOAA, National Weather Service, Silver Spring, MD.

Rahman, A., Weinmann, P. E., Hoang, T. M. T. and Laurenson, E. M. (2002) Monte Carlo simulation of flood frequency curves from rainfall. J. Hydrol., 256, 196-210.

Reed, D. W., Faulkner, D. S. and Stewart, E. J. (1999) The FORGEX method of rainfall growth estimation - II: Description. Hydrol. and Earth System Sci., 3, 197203.

Reed, D. W. and Stewart, E. J. (1989) Focus on rainfall growth estimation. Proc. $2^{\text {nd }}$ National Hydrol. Symp., Sheffield, UK, September 1989, British Hydrological Society, pp. 3.57-3.65.

Reed, D. W. and Stewart, E. J. (1994) Inter-site and inter-duration dependence in rainfall extremes. In Barnett, V. and Turkman, K. F. (eds.) Statistics for the environment 2: Water related issues, John Wiley \& Sons, 125-143.

Siriwardena, L. and Weinmann, P. E. (1998) A technique to interpolate frequency curves between frequent events and probable maximum events. Report 98/9, December 1998. Cooperative Research Centre for Catchment Hydrology, Monash University, Victoria, Australia, $55 \mathrm{pp}$.

Smithers, J. C. and Schulze, R. E. (2000) Development and evaluation of techniques for estimating short duration design rainfall in South Africa. WRC Report No.

681/1/00, Water Research Commission, Pretoria, South Africa. 356 pp.

Smithers, J. C. and Schulze, R. E. (2003) Design rainfall and flood estimation in South Africa. WRC Report No. 1060/1/03, Water Research Commission, Gezina, South Africa. $156 \mathrm{pp}$.

Smithers, J. C. and Schulze, R. E. (2004) The estimation of design rainfalls for South Africa using a regional scale invariant approach. Proc. of the British Hydrological Society's conference "Hydrology: Science \& Practice for the $21^{\text {st }}$ Century", Vol. 1. London, July 2004.

Stedinger, J. R., Vogel, R. M. and Foufoula-Giorgiou, E. (1993) Frequency analysis of extreme events. In: D. R. Maidment (ed.), Handbook of Hydrology. McGraw-Hill, London.

Stewart, E. J., Jones, D. A., Svensson, C., Morris. D. G., Dempsey, P., Dent, J. E., Collier, C. G. and Anderson, C. A. (2009) Reservoir safety - Long return period rainfall. Draft final report to Defra, project WS194/2/39 (Reservoir Safety - Long Return Period Rainfall). Centre for Ecology \& Hydrology, Wallingford, July 2009. 
Svensson, C. and Jones, D. A. (2010) Review of methods for deriving areal reduction factors. J. Flood Risk Manag., DOI: 10.1111/j.1753-318X.2010.01075.x.

Tabony, R.C. (1983) Extreme value analysis in meteorology. Met. Mag., 112, 77-98.

Thompson, C. S. (1992) HIRDS (Manual and software). National Institute of Water and Atmospheric Research, Wellington, New Zealand.

Thompson, C. S. (2002) The high intensity rainfall design system: HIRDS. Proc. Int. Conf. on Flood Estimation, Bern, Switzerland, 6-8 March 2002.

Vedin, H. and Eriksson B. (1988) Extrem arealnederbörd i Sverige 1881-1988. SMHI Metorologi Nr 76. Swedish Meteorological and Hydrological Institute, Norrköping, Sweden.

Weinmann, P. E., Nandakumar, N., Siriwardena, L., Mein, R. G. and Nathan, R. J. (1999) Estimation of rare design rainfalls for Victoria using the CRC-FORGE methodology. Proc. Water99 Joint Congress, Brisbane, 6-8 July 1999, Inst. of Eng. Australia, pp. 284-289. 
Table 1. Characteristics of rainfall frequency estimation methods used in different countries.

\begin{tabular}{|c|c|c|c|c|c|c|}
\hline 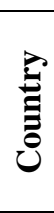 & $\begin{array}{l}\text { Name / } \\
\text { Refer- } \\
\text { ences }\end{array}$ & $\begin{array}{l}\text { Return } \\
\text { period } \\
\text { (years) }\end{array}$ & $\begin{array}{l}\text { Dur- } \\
\text { ation }\end{array}$ & $\begin{array}{l}\text { Statistical } \\
\text { distribution } \\
\text { /fitting } \\
\text { technique/ } \\
\text { data }\end{array}$ & Method & Comments \\
\hline \multirow[t]{2}{*}{ 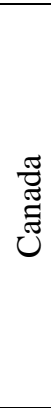 } & $\begin{array}{l}\text { Hogg et al. } \\
(1989) ; \\
\text { Hogg and } \\
\text { Carr } \\
(1985)\end{array}$ & $2-100$ & $\begin{array}{l}5 \text { min }- \\
24 \text { hours }\end{array}$ & $\begin{array}{l}\text { Gumbel; } \\
\text { method of } \\
\text { moments; } \\
\text { AM }\end{array}$ & $\begin{array}{l}\text { Up-to-date IDF values for } 549 \text { individual locations, } \\
\text { earlier estimates presented as mapped values of the } \\
\text { Gumbel parameters. Upward adjustment in } \\
\text { mountainous areas, with different factors for onshore } \\
\text { coastal and non-coastal mountains. Rainfall plus } \\
\text { snowmelt are dealt with separately }\end{array}$ & $\begin{array}{l}\text { Product moments are sensitive to outliers, but the two- } \\
\text { parameter Gumbel distribution reduces this effect. A } \\
\text { distribution with more parameters may better represent } \\
\text { the data. L-moments and PWM are considered to give } \\
\text { a more robust fit than product moments. Mapping of } \\
\text { the parameters give spatial smoothing although there is } \\
\text { no formal regionalisation }\end{array}$ \\
\hline & $\begin{array}{l}\text { Hogg and } \\
\text { Carr } \\
(1985) \\
\end{array}$ & PMP & $\begin{array}{l}1,6 \text { and } \\
24 \text { hours }\end{array}$ & $\begin{array}{l}\text { A variant of } \\
\text { the above }\end{array}$ & $\begin{array}{l}\text { Frequency factors estimated according to Hershfield } \\
\text { (1977) }\end{array}$ & Method combines information across several countries \\
\hline \multirow{3}{*}{$\begin{array}{l}\frac{1}{0} \\
\frac{D}{2} \\
3 \\
n\end{array}$} & $\begin{array}{l}\text { Lennart } \\
\text { Wern, } \\
\text { SMHI, } \\
\text { pers. } \\
\text { comm. }\end{array}$ & $\begin{array}{l}\text { Up to a } \\
\text { few } \\
\text { hundred }\end{array}$ & Daily & $\begin{array}{l}\text { Gumbel } \\
\text { (regression } \\
\text { line fit) and } \\
\text { GEV } \\
\text { (PWM); AM }\end{array}$ & $\begin{array}{l}\text { At-site estimates. If short series, shape parameter of } \\
\text { GEV is averaged for nearby sites. Rainfall estimates } \\
\text { for sub-daily durations can be derived for return } \\
\text { periods } \leq 10 \text { years }\end{array}$ & $\begin{array}{l}\text { There is no formal regionalisation, but information on } \\
\text { the shape parameter from nearby sites gives more } \\
\text { stable estimates. See comments for Canada regarding } \\
\text { distributions and fitting methods }\end{array}$ \\
\hline & $\begin{array}{l}\text { Alexanders } \\
\text { on } \text { et al. } \\
(2001)\end{array}$ & $\begin{array}{l}\text { Up to a } \\
\text { few } \\
\text { thousand }\end{array}$ & Daily & $\begin{array}{l}\text { GEV; PWM; } \\
\text { AM }\end{array}$ & Station-year method for homogeneous regions & $\begin{array}{l}\text { Regionalisation is used. Buishand (1984) suggests }>30 \\
\mathrm{~km} \text { separation between gauges to achieve } \\
\text { independence criterion for station-year method }\end{array}$ \\
\hline & $\begin{array}{l}\text { Bergström } \\
\text { et al. } \\
\text { (1989), } \\
\text { Norstedt et } \\
\text { al. (1992) }\end{array}$ & $\sim 10,000$ & $\begin{array}{l}\text { 14-day } \\
\text { sequence } \\
\text { containin } \\
\text { g the } \\
\text { largest } \\
\text { observed } \\
\text { amounts } \\
\text { over } 24 \\
\text { hours to }\end{array}$ & & $\begin{array}{l}\text { Deterministic 14-day rainfall sequences specific to } \\
\text { each of five climatological regions, based on } \\
\text { observed areal daily rainfalls for } 1,000 \text { and } 10,000 \\
\mathrm{~km}^{2} \text { in } 1881-1988 \text {. Adjustments for season, } \\
\text { catchment area and elevation }\end{array}$ & $\begin{array}{l}\text { Investigation of areal rainfalls means good } \\
\text { understanding of meteorological causes. No rigorous } \\
\text { estimate of the frequency associated with the 14-day } \\
\text { sequence }\end{array}$ \\
\hline
\end{tabular}




\begin{tabular}{|c|c|c|c|c|c|c|}
\hline & & & 14 days. & & & \\
\hline \multirow{2}{*}{ 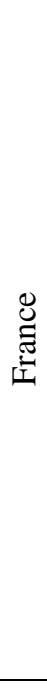 } & $\begin{array}{l}\text { Météo- } \\
\text { France } \\
\text { (2007) }\end{array}$ & $<100$ & $\begin{array}{l}6 \text { min }- \\
10 \text { days }\end{array}$ & $\begin{array}{l}\text { Long series } \\
\text { ( } \geq 25 \text { years): } \\
\text { GEV; PWM; } \\
\text { AM. } \\
\text { Short series } \\
\text { ( } \geq 10 \text { years): } \\
\text { GP fitted to } \\
\text { POT }\end{array}$ & At-site estimates & $\begin{array}{l}\text { There is no regionalisation and hence no transfer of } \\
\text { information from nearby sites. See comments for } \\
\text { Canada }\end{array}$ \\
\hline & $\begin{array}{l}\text { GRADEX/ } \\
\text { FRCOLD } \\
(1994), \\
\text { Kieffer and } \\
\text { Bois } \\
(1997)\end{array}$ & $\begin{array}{l}10- \\
10,000\end{array}$ & $>4$ hours & $\begin{array}{l}\text { Gumbel; } \\
\text { regression } \\
\text { line fitted to } \\
\text { annual and } \\
\text { seasonal } \\
\text { maxima } \\
\text { plotted on } \\
\text { Gumbel } \\
\text { scale }\end{array}$ & $\begin{array}{l}\text { Point or areal rainfalls. Seasonal frequency } \\
\text { distributions can be multiplied to obtain annual } \\
\text { frequency estimates }\end{array}$ & $\begin{array}{l}\text { The Gumbel distribution may not capture the } \\
\text { characteristics of the data. There is no regionalisation }\end{array}$ \\
\hline \multirow[t]{2}{*}{ 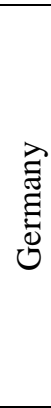 } & $\begin{array}{l}\text { KOSTRA/ } \\
\text { Bartels } \text { et } \\
\text { al. }(1997)\end{array}$ & $0.5-100$ & $\begin{array}{l}5 \text { min }- \\
72 \text { hours }\end{array}$ & $\begin{array}{l}\text { Gumbel with } \\
\text { AM, and } \\
\text { exponential } \\
\text { with POT } \\
\text { series. } \\
\text { Regression } \\
\text { line fit }\end{array}$ & $\begin{array}{l}\text { The results are presented on a } 8.45 \mathrm{~km} \text { grid. } \\
\text { Snowmelt is considered separately. The spatial } \\
\text { interpolation methods are different for summer, } \\
\text { winter and the whole year }\end{array}$ & $\begin{array}{l}\text { Seasonal analysis separates out the dominant rainfall } \\
\text { characteristics to obtain more homogeneous regions }\end{array}$ \\
\hline & $\begin{array}{l}\text { Bartels et } \\
\text { al. (1997) }\end{array}$ & $\begin{array}{l}100- \\
\text { PMP }\end{array}$ & & & $\begin{array}{l}\text { Extrapolation of the KOSTRA regression line, but } \\
\text { using a steeper slope }\end{array}$ & $\begin{array}{l}\text { The need for a steeper slope at high return periods may } \\
\text { suggest that a distribution with more than two } \\
\text { parameters could be suitable }\end{array}$ \\
\hline
\end{tabular}




\begin{tabular}{|c|c|c|c|c|c|c|}
\hline 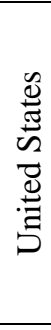 & $\begin{array}{l}\text { Perica } \text { et } \\
\text { al. }(2009)\end{array}$ & $1-1000$ & $\begin{array}{l}5 \text { min }- \\
60 \text { days }\end{array}$ & $\begin{array}{l}\text { Different } \\
\text { probability } \\
\text { distributions } \\
\text { for each } \\
\text { region and } \\
\text { duration; } \\
\text { L-moments; } \\
\text { AM }\end{array}$ & $\begin{array}{l}\text { Index-flood approach, with the mean AM rainfall as } \\
\text { the index (gridded). Growth curves for homogeneous } \\
\text { regions defined using cluster analysis based on } \\
\text { topography and climatology of extreme events. } \\
\text { Information on temporal distributions and seasonality } \\
\text { are provided }\end{array}$ & $\begin{array}{l}\text { Care needs to be taken to obtain smooth transitions } \\
\text { across the fixed-boundary regions. Using the mean } \\
\text { rather than the median makes the estimate more } \\
\text { sensitive to outliers. L-moments give robust parameter } \\
\text { estimates, which is needed for distributions with many } \\
\text { parameters }\end{array}$ \\
\hline 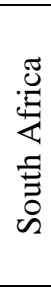 & $\begin{array}{l}\text { Smithers } \\
\text { and } \\
\text { Schulze } \\
(2003 \text {, } \\
2004)\end{array}$ & $2-200$ & $\begin{array}{l}5 \min -7 \\
\text { days }\end{array}$ & $\begin{array}{l}\text { GEV; } \\
\text { L-moments; } \\
\text { AM }\end{array}$ & $\begin{array}{l}\text { Index-flood approach with the mean AM rainfall as } \\
\text { the index. Regressions on mean annual precipitation, } \\
\text { latitude and altitude to estimate the index at any } \\
\text { location. Homogeneous fixed-boundary regions from } \\
\text { cluster analysis based on geography and climatology. } \\
\text { Information from the 1-day growth curve is used also } \\
\text { for other durations }\end{array}$ & $\begin{array}{l}\text { See comment for the United States. The transfer of } \\
\text { information from the 1-day growth curve to the curves } \\
\text { for sub-daily durations makes use of the greater } \\
\text { reliability and abundance of daily compared with } \\
\text { shorter-duration records }\end{array}$ \\
\hline 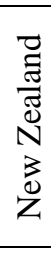 & $\begin{array}{l}\text { HIRDS/ } \\
\text { Thompson } \\
\text { (1992, } \\
\text { 2002) }\end{array}$ & $2-150$ & $\begin{array}{l}10 \text { min }- \\
72 \text { hours }\end{array}$ & $\begin{array}{l}\text { GEV; PWM, } \\
\text { with longer } \\
\text { records } \\
\text { getting a } \\
\text { larger } \\
\text { weight; AM }\end{array}$ & $\begin{array}{l}\text { Index-flood approach with the median AM rainfall as } \\
\text { the index. The index is mapped using a smoothing } \\
\text { spline with geographical covariates. Growth curve for } \\
60 \mathrm{~km} \text { radius "region of influence" centred on each } \\
\text { site }\end{array}$ & $\begin{array}{l}\text { The "region of influence" approach avoids transition } \\
\text { problems across fixed boundaries. PWMs give robust } \\
\text { parameter estimates. More weight to long than short } \\
\text { records makes estimates more robust }\end{array}$ \\
\hline \multirow[t]{2}{*}{ 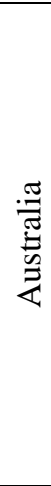 } & $\begin{array}{l}\text { CRC- } \\
\text { FORGE/ } \\
\text { Weinmann } \\
\text { et al. } \\
(1999)\end{array}$ & $\begin{array}{l}50- \\
2000\end{array}$ & $\begin{array}{l}6-120 \\
\text { hours }\end{array}$ & $\begin{array}{l}\text { GEV; least } \\
\text { squares } \\
\text { fitting } \\
\text { method; AM }\end{array}$ & $\begin{array}{l}\text { Index-flood method with the 50-year return period } \\
\text { rainfall as the index. All the standardised data in the } \\
\text { region are pooled into a single long series in a } \\
\text { station-year approach. Circular regions expand } \\
\text { around the site, each progressively larger region used } \\
\text { to estimate a particular section of the growth curve. } \\
\text { The size of each region is determined by them } \\
\text { containing a specified number of gauges. Spatial } \\
\text { dependence in the data is accounted for }\end{array}$ & $\begin{array}{l}\text { Using the 50-year return period rainfall as index may } \\
\text { result in larger uncertainty than if the median had been } \\
\text { used. Expanding regions make good use of data, } \\
\text { focuses on local data as well as bringing in regional } \\
\text { information for higher return periods, and avoids } \\
\text { boundary problems. The model allows the spatial } \\
\text { dependence to decrease with increasing return period, } \\
\text { which seems realistic }\end{array}$ \\
\hline & $\begin{array}{l}\text { Siriwarden } \\
\text { a and } \\
\text { Weinmann }\end{array}$ & $\begin{array}{l}2000- \\
\text { PMP }\end{array}$ & & & $\begin{array}{l}\text { Procedure to fill the gap between the 2000-year } \\
\text { rainfall, estimated as above, and PMP. A 2-parameter } \\
\text { parabolic function is fitted in log-log space between }\end{array}$ & This seems to be a pragmatic approach \\
\hline
\end{tabular}




\begin{tabular}{|c|c|c|c|c|c|c|}
\hline & (1998) & & & & $\begin{array}{l}\text { the two values. PMP is assigned a return period } \\
\text { between } 10,000 \text { and } 10,000,000 \text { years depending on } \\
\text { catchment size }\end{array}$ & \\
\hline & $\begin{array}{l}\text { Flood } \\
\text { Studies } \\
\text { Report/ } \\
\text { NERC } \\
(1975)\end{array}$ & $\begin{array}{l}\text { Currently } \\
\text { used for } \\
\text { return } \\
\text { periods } \\
\geq 1000 \\
\text { years }\end{array}$ & $\begin{array}{l}1 \mathrm{~min}- \\
25 \text { days }\end{array}$ & $\begin{array}{l}\text { Graphical fit } \\
\text { to results of } \\
\text { quartile } \\
\text { analysis of } \\
\text { AM }\end{array}$ & $\begin{array}{l}\text { Index-flood approach using the 5-year return period } \\
\text { rainfall as index. The UK is divided into only two } \\
\text { regions, but within each region the growth curve } \\
\text { depends on the magnitude of the index }\end{array}$ & $\begin{array}{l}\text { Involved method relying in part on graphical methods. } \\
\text { Does not capture local variations well. }\end{array}$ \\
\hline 光 & $\begin{array}{l}\text { Flood } \\
\text { Estimation } \\
\text { Handbook/ } \\
\text { Faulkner } \\
(1999)\end{array}$ & $\begin{array}{l}\text { Currently } \\
\text { used for } \\
\text { return } \\
\text { periods } \\
\leq 1000 \\
\text { years, } \\
\text { but } \\
\text { software } \\
\text { allows } \\
\text { estimates } \\
\text { up to } \\
10,000 \\
\text { years } \\
\text { return } \\
\text { period }\end{array}$ & $\begin{array}{l}1 \text { hour }- \\
8 \text { days }\end{array}$ & $\begin{array}{l}\text { Initially } \\
\text { linear } \\
\text { segments are } \\
\text { fitted to AM } \\
\text { by a least- } \\
\text { squares } \\
\text { technique, } \\
\text { after which a } \\
\text { depth- } \\
\text { duration- } \\
\text { frequency } \\
\text { model (log- } \\
\text { Gumbel) is } \\
\text { fitted by a } \\
\text { least-squares } \\
\text { method to } \\
\text { avoid } \\
\text { contradiction } \\
\text { s between } \\
\text { durations or } \\
\text { return } \\
\text { periods }\end{array}$ & $\begin{array}{l}\text { Index-flood approach using the median AM rainfall } \\
\text { as index. Circular regions expand around the site (up } \\
\text { to } 200 \mathrm{~km} \text { radius), each progressively larger region } \\
\text { used to estimate a particular section of the growth } \\
\text { curve. Network maxima as well as series at } \\
\text { individual gauges are used. Spatial dependence in the } \\
\text { data is accounted for }\end{array}$ & $\begin{array}{l}\text { Expanding regions make good use of data, focuses on } \\
\text { local data as well as bringing in regional information } \\
\text { for higher return periods, and avoids boundary } \\
\text { problems. The model does not allow spatial } \\
\text { dependence to vary with return period, which seems } \\
\text { counter-intuitive. Extrapolation using a log-Gumbel } \\
\text { distribution results in } 10,000 \text {-year return period } \\
\text { rainfalls not infrequently exceeding PMP }\end{array}$ \\
\hline & & & & & & \\
\hline
\end{tabular}

